Review

\title{
Oral Semaglutide, the First Ingestible Glucagon-Like Peptide-1 Receptor Agonist: Could It Be a Magic Bullet for Type 2 Diabetes?
}

\author{
Hwi Seung Kim ${ }^{1,2}$ and Chang Hee Jung $1,2, * \mathbb{C}$ \\ 1 Asan Medical Center, Department of Internal Medicine, University of Ulsan College of Medicine, \\ Seoul 05505, Korea; jennyhsk212@gmail.com \\ 2 Asan Diabetes Center, Asan Medical Center, Seoul 05505, Korea \\ * Correspondence: chjung0204@gmail.com
}

Citation: Kim, H.S.; Jung, C.H. Oral Semaglutide, the First Ingestible Glucagon-Like Peptide-1 Receptor Agonist: Could It Be a Magic Bullet for Type 2 Diabetes? Int. J. Mol. Sci. 2021, 22, 9936. https://doi.org/ $10.3390 /$ ijms 22189936

Academic Editor: Bunzo Matsuura

Received: 30 August 2021

Accepted: 12 September 2021

Published: 14 September 2021

Publisher's Note: MDPI stays neutral with regard to jurisdictional claims in published maps and institutional affiliations.

Copyright: () 2021 by the authors. Licensee MDPI, Basel, Switzerland. This article is an open access article distributed under the terms and conditions of the Creative Commons Attribution (CC BY) license (https:// creativecommons.org/licenses/by/ $4.0 /)$.

\begin{abstract}
The gastrointestinal tract secretes gut hormones in response to food consumption, and some of these stimulate insulin secretion. Glucagon-like peptide-1 (GLP-1) is an incretin peptide hormone released from the lower digestive tract that stimulates insulin secretion, suppresses glucagon secretion, and decreases hunger. GLP-1 receptor agonist (GLP-1RA) mimics the action of endogenous GLP-1, consequently reversing hyperglycemia and causing weight reduction, demonstrating its efficacy as an antidiabetic and antiobesity agent. Previously restricted to injection only, the invention of the absorption enhancer sodium N-(8-[2-hydroxybenzoyl]amino) caprylate resulted in the development of oral semaglutide, the first ingestible GLP-1RA. Oral semaglutide demonstrated its efficacy in glycemic management and body weight loss with a low risk of hypoglycemia as a monotherapy and in combination with other hypoglycemic medications in its clinical trial programs named Peptide Innovation for Early Diabetes Treatment. Consistent with other injectable GLP-1RAs, gastrointestinal side effects were often reported. Additionally, cardiovascular safety was established by demonstrating that oral semaglutide was not inferior to a placebo in terms of cardiovascular outcomes. Thus, oral semaglutide represents a novel treatment option that is particularly well-suited for patients with type 2 diabetes and/or obesity.
\end{abstract}

Keywords: semaglutide; GLP-1 receptor; type 2 diabetes; obesity

\section{Introduction}

Type 2 diabetes (T2D) is a chronic metabolic condition characterized by beta-cell dysfunction and insulin resistance that worsens over time [1]. T2D is treated with a combination of lifestyle adjustments, such as diet and exercise, as well as medication intervention [1]. Over the recent decade, new antidiabetic drugs have been introduced, expanding T2D therapy choices while also increasing treatment complexity [1,2]. Along with the development of novel agents, recent guidelines stress the patient's coexisting diseases and risk factors before glycemic control, recommending medications with cardiovascular and renal benefits over those with glycemic control [2-4].

Obesity is a substantial risk factor for having T2D, and the prevalence of T2D is projected to rise as the world's obese population grows [5]. Obesity is a modifiable risk factor, hence, correcting the etiology of obesity and insulin resistance may help prevent and treat T2D [5]. Although lifestyle changes, including diet and exercise, are essential for T2D treatment, most patients with T2D require the use of antidiabetic drugs to achieve their glycemic goals. Metformin, sulfonylureas, meglitinides, thiazolidinediones, alphaglucosidase inhibitors, and insulin are examples of traditional agents [1]. While these medications can effectively lower blood glucose levels, many have limitations due to weight gain and hypoglycemia [1]. Furthermore, only metformin and thiazolidinediones are used to improve insulin sensitivity and affect the pathophysiology of T2D [1]. As a 
result, unmet needs in the treatment of T2D persist, necessitating additional research to develop new treatment choices.

\subsection{Gut Hormones: The Metabolism Regulators}

Gut hormones are involved in metabolism and interact with one another to digest the nutrients that are consumed [6] (Figure 1). Two major hormones that induce insulin production are glucose-dependent insulinotropic polypeptide (GIP) and glucagon-like peptide-1 (GLP-1) [7]. Ghrelin, on the other hand, is a stomach hormone that inhibits insulin secretion by releasing growth hormone [8]. Cholecystokinin, GLP-1, and peptide YY are hormones that slow down stomach emptying and suppress appetite $[9,10]$. Glucagon is produced in the pancreatic alpha cells and increases hepatic glucose synthesis and lipolysis to boost blood glucose levels [11]. Pancreatic polypeptide excreted from the pancreas is involved in the long-term regulation of appetite [10]. Oxyntomodulin, released concurrently with GLP-1 by the L-cells, reduces food intake while increasing energy consumption and insulin secretion $[12,13]$. The aforementioned gut hormones are being studied in order to find new potential medications to address the unmet demand in T2D treatment.

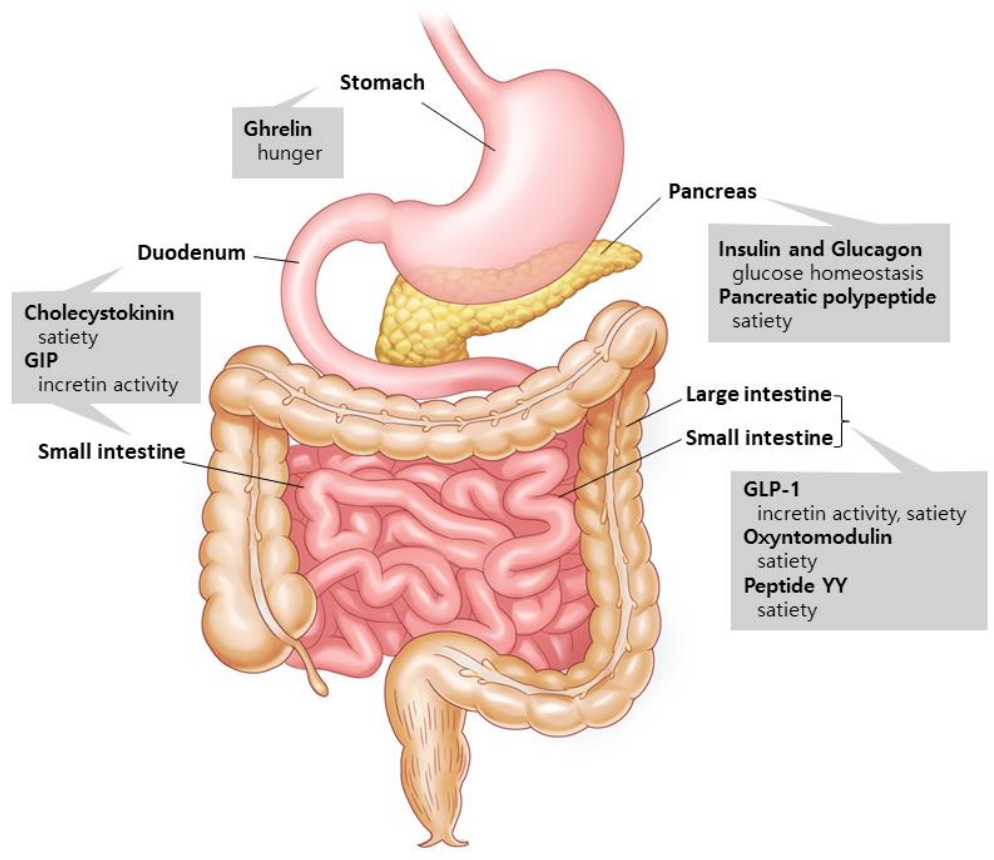

Figure 1. Gut hormones and their supposed actions. Ghrelin is released by the stomach. Insulin, glucagon, and pancreatic polypeptide are excreted from the pancreas. Cholecystokinin and GIP are secreted in the duodenum and small intestines, and GLP-1, oxyntomodulin, and peptide YY are released by the small and large intestines. These hormones from the gastrointestinal tract communicate with the peripheral and central nervous systems to control a variety of metabolic activities. Modified from Murphy et al. [6].

\subsection{Glucagon-like Peptide-1 (GLP-1): An Innovator for Gut Hormone Therapies}

The release of incretin hormones after eating a meal has opened new avenues for the development of antidiabetic drugs [14]. Incretins promote insulin release from pancreatic beta cells in response to hyperglycemia, preserving normoglycemia [15]. Both GIP and GLP-1, which are each released by K-cells in the duodenum and upper jejunum and by L-cells in the distal ileum and large intestines, enhance glucose-mediated insulin release $[16,17]$. In patients with T2D, however, GIP loses much of its insulinotropic activity, whereas GLP-1 demonstrates a sustained but diminished insulinotropic response [18]. Furthermore, while GLP-1 reduces glucagon secretion in a glucose-dependent manner, GIP 
has no effect on glucagon secretion during hyperglycemia and instead increases it during hypoglycemia [19]. GLP-1 has also been demonstrated to have pleiotropic effects, such as lowering hunger and food intake, as well as slowing stomach emptying and small bowel movement $[20,21]$. As a result, GLP-1 has become a hot target for possible T2D and obesity medicines.

GLP-1 receptor agonist (GLP-1RA) decreases food intake by increasing gastric emptying time and satiety, resulting in body weight loss [22]. Despite its antidiabetic and antiobesity properties, the GLP-1RA has been restricted in usage because of gastrointestinal side effects (nausea, vomiting, constipation, and abdominal discomfort) [7]. Furthermore, despite its established efficacy, the subcutaneous injection technique of administering GLP-1RA has further limited its prescription. Concerns with injection, including pain and fear, have been noted in studies as barriers to maintaining GLP-1RA in real-world practice $[23,24]$. As a result, the first oral GLP-1RA semaglutide is a significant achievement, offering a practical alternative to injectables for patients with T2D.

The goal of this review was to describe the pharmacology, efficacy, safety, and clinical implications of oral semaglutide, the first ingestible gut hormone derivative, as a T2D treatment.

\section{Pharmacodynamics and Pharmacokinetics of Oral Semaglutide}

Semaglutide was originally designed as a once-weekly subcutaneous long-acting GLP-1RA. Semaglutide is a human GLP-1 analog with $94 \%$ similarity to natural human GLP-1 but has amino acid changes that improve albumin binding, decrease renal clearance, and boost resistance to DPP-4 destruction [25]. Semaglutide demonstrated efficacy in glycemic control and body weight reduction compared to placebo and active comparators, such as sitagliptin, exenatide extended-release, dulaglutide, and insulin glargine, in the Semaglutide Unabated Sustainability in Treatment of Type 2 Diabetes (SUSTAIN) clinical trials [26-30]. Furthermore, semaglutide improved cardiovascular outcomes significantly [31].

As the peptide-based drug is degraded by proteolytic enzymes and the $\mathrm{pH}$ of the gastrointestinal tract, semaglutide must be injected subcutaneously. Semaglutide could be developed as an oral tablet by combining it with an absorption enhancer known as sodium $\mathrm{N}$-(8-[2-hydroxybenzoyl]amino) caprylate (SNAC) [32,33] (Figure 2). In a concentrationdependent manner, SNAC forms a noncovalent bond with GLP-1, increasing lipophilicity and transcellular absorption of semaglutide through the stomach epithelium [32,34]. Additionally, in the acidic environment of the stomach, SNAC acts as a local $\mathrm{pH}$ buffer for semaglutide, increasing solubility and protecting the drug from degradation [34]. As SNAC's activity is brief and reversible, it separates from the medication once it reaches the bloodstream [32].

In contrast to most other medications absorbed in the intestines, oral semaglutide has a distinct pharmacokinetic profile since it is virtually fully absorbed in the stomach. After 15-35 min of oral intake, the medication reaches its maximal concentration [32]. As food interferes with drug absorption, oral semaglutide should be given while fasting [35]. Semaglutide exposure was unaffected by the amount of water used to take the drug [35]. However, the higher the semaglutide exposure, the longer the post-dose fasting time; hence, at least $30 \mathrm{~min}$ of post-dose fasting is recommended [35]. Renal and hepatic impairment had no effect on the pharmacokinetics of oral semaglutide, indicating that individuals with renal and hepatic impairment do not require dose adjustments [36,37]. In investigations involving omeprazole, lisinopril, warfarin, digoxin, metformin, levonorgestrel, ethinyl estradiol, furosemide, and rosuvastatin, no significant drug-drug interactions were found [38-40]. Thyroid function tests should be monitored in patients receiving both oral semaglutide and levothyroxine since the pharmacokinetics of levothyroxine are influenced by a $33 \%$ increase in exposure when taken with oral semaglutide [41]. 


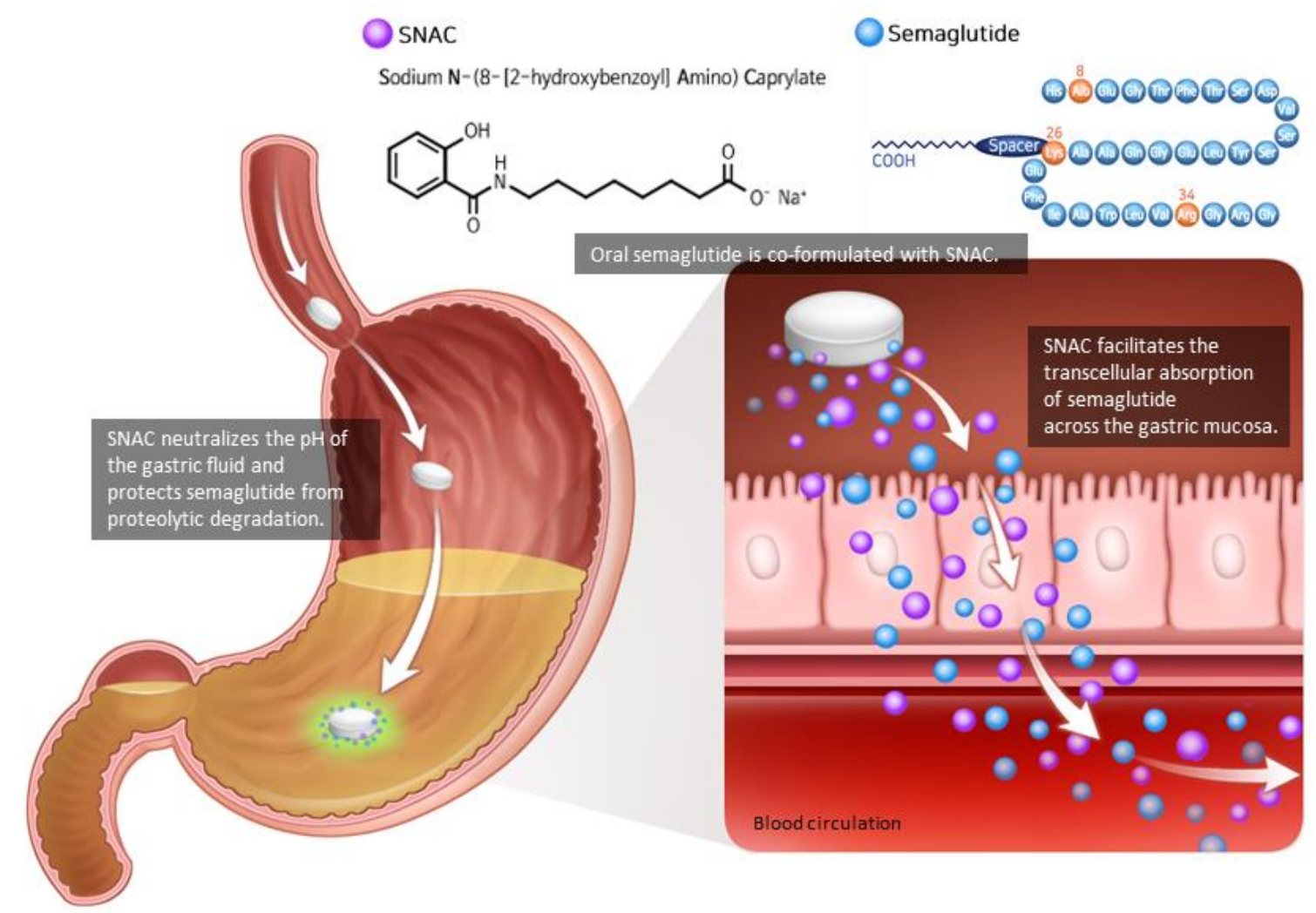

Figure 2. Oral semaglutide and SNAC. Oral semaglutide must be co-formulated with the absorption enhancer SNAC in order to be absorbed. SNAC raises the local $\mathrm{pH}$, resulting in increased solubility and protection from proteolytic degradation. SNAC promotes the absorption of semaglutide across the gastric mucosa in a time- and concentration-dependent manner, which is totally reversible. Modified from Andersen et al. [33].

\section{Clinical Efficacy and Safety: Summary of Peptide Innovation for Early Diabetes Treatment (PIONEER) Trials}

The PIONEER program was composed of phase 3 clinical trials to compare the clinical efficacy and safety of oral semaglutide against placebo and other medications. The program included 10 trials, eight of which were global and two of which were solely undertaken in Japan. The PIONEER studies, which began in 2016 and ended in 2018, enrolled 9543 participants (1293 Japanese patients). The PIONEER program used two estimands established by the International Council of Harmonisation to evaluate the efficacy objectives: "treatment policy" and "trial product" [42]. The treatment policy estimand is based on the intention-to-treat principle and covers all randomized patients, even those who stopped taking the test medicine and added or switched to something else. The trial product estimand, on the other hand, assesses the therapeutic efficacy of individuals who stayed on the test drug without receiving any rescue medication. This review focuses mostly on the treatment policy estimand. The results of the PIONEER program regarding $\mathrm{HbA1c}$ and weight reduction are each presented in Tables 1 and 2. 
Table 1. Summary of efficacy in glycemic control across the PIONEER trials [43-51].

\begin{tabular}{|c|c|c|c|c|c|c|c|c|}
\hline & \multirow{3}{*}{$\begin{array}{l}\text { Time } \\
\text { (wk) }\end{array}$} & \multirow{3}{*}{$\begin{array}{c}\text { No. of } \\
\text { Patients } \\
\text { (Japanese) }\end{array}$} & \multirow{3}{*}{ Comparator } & \multirow{3}{*}{$\begin{array}{c}\text { Baseline } \\
\text { HbA1c (\%) }\end{array}$} & \multicolumn{4}{|c|}{ Mean Reduction in HbA1c (\%) } \\
\hline & & & & & \multicolumn{3}{|c|}{ Semaglutide } & \multirow{2}{*}{ Comparator } \\
\hline & & & & & $3 \mathrm{mg}$ & $7 \mathrm{mg}$ & $14 \mathrm{mg}$ & \\
\hline PIONEER 1 & 26 & $703(116)$ & Placebo & 8.0 & $-0.9^{*}$ & $-1.2 *$ & $-1.4^{*}$ & -0.3 \\
\hline PIONEER 2 & 52 & $822(0)$ & Empagliflozin $25 \mathrm{mg}$ & 8.1 & & & $-1.3 *$ & -0.9 \\
\hline PIONEER 3 & 78 & $1864(207)$ & Sitagliptin $100 \mathrm{mg}$ & 8.3 & -0.6 & $-1.0^{*}$ & $-1.3^{*}$ & -0.8 \\
\hline PIONEER 4 & 52 & $711(75)$ & $\begin{array}{c}\text { Liraglutide } 1.8 \mathrm{mg} \text { or } \\
\text { placebo }\end{array}$ & 8.0 & & & -1.2 & $\begin{array}{c}-1.1 \text { (liraglutide) } \\
-0.2 \text { (placebo) }\end{array}$ \\
\hline PIONEER 5 & 26 & $324(0)$ & Placebo (renal) & 8.0 & & & $-1.0 *$ & -0.2 \\
\hline PIONEER 7 & 52 & $504(0)$ & Sitagliptin $100 \mathrm{mg}$ & 8.3 & \multicolumn{3}{|c|}{$-1.3 *$ (flexible dosing) } & -0.8 \\
\hline PIONEER 8 & 52 & 731 (194) & $\begin{array}{l}\text { Placebo (add-on to } \\
\text { insulin) }\end{array}$ & 8.2 & $-0.6^{*}$ & $-0.9 *$ & $-1.3^{*}$ & -0.1 \\
\hline PIONEER 9 & 52 & $243(243)$ & $\begin{array}{l}\text { Liraglutide } 0.9 \mathrm{mg} \text { or } \\
\text { placebo }\end{array}$ & 8.2 & $-0.9^{\mathbb{I}}$ & $-1.4^{\mathbb{I}}$ & $-1.5^{\mathbb{I}}$ & $\begin{array}{l}-1.2 \text { (liraglutide) } \\
-0.1 \text { (placebo) }\end{array}$ \\
\hline PIONEER 10 & 52 & $458(458)$ & Dulaglutide $0.75 \mathrm{mg}$ & 8.3 & $-0.9 *$ & -1.4 & $-1.7^{*}$ & -1.4 \\
\hline
\end{tabular}

* Statistically significant compared to the comparator. ${ }^{\text {II }}$ Statistically significant compared to the placebo.

Table 2. Summary of efficacy in weight reduction across the PIONEER trials [43-51].

\begin{tabular}{|c|c|c|c|c|c|c|c|c|}
\hline & \multirow{3}{*}{$\begin{array}{l}\text { Time } \\
(w k)\end{array}$} & \multirow{3}{*}{$\begin{array}{c}\text { No. of } \\
\text { Patients } \\
\text { (Japanese) }\end{array}$} & \multirow{3}{*}{ Comparator } & \multirow{3}{*}{$\begin{array}{c}\text { Baseline } \\
\text { Weight (kg) }\end{array}$} & \multicolumn{4}{|c|}{ Mean Reduction in Weight (kg) } \\
\hline & & & & & \multicolumn{3}{|c|}{ Semaglutide } & \multirow{2}{*}{ Comparator } \\
\hline & & & & & $3 \mathrm{mg}$ & $7 \mathrm{mg}$ & $14 \mathrm{mg}$ & \\
\hline PIONEER 1 & 26 & $703(116)$ & Placebo & 88.1 & -1.5 & -2.3 & $-3.7 *$ & -1.4 \\
\hline PIONEER 2 & 52 & $822(0)$ & Empagliflozin $25 \mathrm{mg}$ & 91.6 & & & -3.8 & -3.7 \\
\hline PIONEER 3 & 78 & $1864(207)$ & Sitagliptin $100 \mathrm{mg}$ & 91.2 & $-1.2^{*}$ & $-2.2 *$ & $-3.1 *$ & -0.6 \\
\hline PIONEER 4 & 52 & $711(75)$ & $\begin{array}{l}\text { Liraglutide } 1.8 \mathrm{mg} \text { or } \\
\text { placebo }\end{array}$ & 94.0 & & & $-4.4^{*}$ & $\begin{array}{c}-3.1 \text { (liraglutide) } \\
-0.2 \text { (placebo) }\end{array}$ \\
\hline PIONEER 5 & 26 & $324(0)$ & Placebo (renal) & 90.8 & & & $-3.4^{*}$ & -0.9 \\
\hline PIONEER 7 & 52 & $504(0)$ & Sitagliptin $100 \mathrm{mg}$ & 88.6 & \multicolumn{3}{|c|}{$-2.6 *$ (flexible dosing) } & -0.7 \\
\hline PIONEER 8 & 52 & $731(194)$ & $\begin{array}{l}\text { Placebo (add-on to } \\
\text { insulin) }\end{array}$ & 85.9 & $-1.4^{*}$ & $-2.4^{*}$ & $-3.7^{*}$ & -0.4 \\
\hline PIONEER 9 & 52 & $243(243)$ & $\begin{array}{l}\text { Liraglutide } 0.9 \mathrm{mg} \text { or } \\
\text { placebo }\end{array}$ & 71.1 & -0.3 & -0.8 & $-2.6^{+, \mathbb{I}}$ & $\begin{array}{c}-0.6 \text { (placebo) } \\
0.0 \text { (liraglutide) }\end{array}$ \\
\hline PIONEER 10 & 52 & $458(458)$ & Dulaglutide $0.75 \mathrm{mg}$ & 72.1 & $-0.0 *$ & $-0.9 *$ & $-1.6^{*}$ & 1.0 \\
\hline
\end{tabular}

${ }^{*}$ Statistically significant compared to the comparator. ${ }^{\dagger}$ Statistically significant compared to liraglutide. ${ }^{\text {II }}$ Statistically significant compared to the placebo.

\subsection{Placebo-Controlled Trials}

\subsubsection{Monotherapy}

The PIONEER 1 trial evaluated the efficacy and safety of oral semaglutide as a monotherapy in patients with T2D who were not taking any antidiabetic drugs [43]. In a 1:1:1:1 ratio, 703 participants were randomly assigned to receive 3,7 , or $14 \mathrm{mg}$ of oral semaglutide or placebo [43]. Participants who were given oral semaglutide began with $3 \mathrm{mg}$ and the dose was gradually raised every 4 weeks until the goal dose was reached [43]. The participants were 55 years old on average, $50.8 \%$ were male, and all had diabetes for mean 3.5 years [43]. At baseline, the mean $\mathrm{HbA1c}$ was $8.0 \%$ and the mean BMI was $31.8 \mathrm{~kg} / \mathrm{m}^{2}$ [43]. When compared to the placebo, oral semaglutide resulted in a larger reduction in $\mathrm{HbA} 1 \mathrm{c}$, with placebo-adjusted differences of $-0.6 \%,-0.9 \%$, and $-1.1 \%$ for 3 , 7 , and $14 \mathrm{mg}$, respectively [43]. The proportions of individuals attaining the target $\mathrm{HbA} 1 \mathrm{c}$ of $<7 \%$ and $\leq 6.5 \%$ were significantly higher in the oral semaglutide group compared to the placebo group $(p<0.001)$ [43]. When compared to the placebo, the $14 \mathrm{mg}$ oral 
semaglutide demonstrated greater weight loss [43]. The placebo-adjusted differences in body weight were $-0.1(p=0.87),-0.9(p=0.09)$, and $-2.3 \mathrm{~kg}(p<0.001)$ for 3,7 , and $14 \mathrm{mg}$, respectively [43]. Oral semaglutide was found to be more efficacious than placebo as a monotherapy in patients with T2D in the PIONEER 1 study, and the side effects were similar to those seen with other injectable GLP-1RAs [43]. Dose-dependent HbA1c and weight reduction was observed in oral semaglutide versus placebo at higher dosages.

\subsubsection{Combination Therapy}

The PIONEER 8 trial enrolled 731 individuals who were using either basal insulin or metformin [44]. Patients with a mean age of 61 years and a diabetes duration of 15 years were randomized to receive oral semaglutide 3,7 , or $14 \mathrm{mg}$ or placebo [44]. Patients were given a $20 \%$ lower insulin dose before starting the study drug, which they continued for 8 weeks until an increase was required [44]. The insulin dose could be modified within the pre-randomization dose during weeks $8-26$, and the insulin dose could be freely adjusted during weeks 26-52 [44]. In comparison with the placebo, the estimated treatment difference (ETD) in the mean change in $\mathrm{HbA} 1 \mathrm{c}$ was $-0.4 \%(p=0.0004),-0.6 \%(p=0.0001)$, and $-0.9 \%(p=0.0001)$ for 3,7 , and $14 \mathrm{mg}$ of oral semaglutide, respectively [44]. At week 52 , all patients taking semaglutide doses lost considerably more weight than those taking the placebo, with ETDs of $-0.8(p=0.0101),-2.5(p<0.0001)$, and $-4.3 \mathrm{~kg}(p<0.0001)$ for 3,7 , and $14 \mathrm{mg}$ of oral semaglutide, respectively [44]. At 52 weeks, oral semaglutide resulted in a statistically significant decrease in total daily insulin dose; in comparison to the placebo, semaglutide $3 \mathrm{mg}$ had -8 units $(p=0.0450)$, semaglutide $7 \mathrm{mg}$ had -16 units $(p<0.0001)$, and semaglutide $14 \mathrm{mg}$ had -17 units $(p<0.0001)$ [44]. Nausea was the most commonly reported side effect in the semaglutide group (11.4-23.2\%) compared to $7.1 \%$ in the placebo group [44]. The PIONEER 8 trial found that oral semaglutide, when combined with insulin and metformin, was effective and safe [44]. Oral semaglutide 7 and $14 \mathrm{mg}$ provided better glycemic control than placebo with lower total daily insulin dosages at both weeks 26 and 52, supporting the use of oral semaglutide to intensify treatment for individuals unable to achieve glycemic target with insulin alone.

\subsection{Active-Comparator Trials}

\subsubsection{Sodium Glucose Co-Transporter 2 (SGLT-2) Inhibitors}

In the PIONEER 2 trial, patients with T2D on metformin monotherapy were compared to those on oral semaglutide and empagliflozin [45]. Oral semaglutide $14 \mathrm{mg}$ and empagliflozin $25 \mathrm{mg}$ were randomly allocated to 412 and 410 patients [45]. The patients were on average 58 years old, $49.5 \%$ were female, and the mean body weight was $91.6 \mathrm{~kg}$ [45]. Oral semaglutide lowered $\mathrm{HbA1c}$ by $1.3 \%$ and empagliflozin by $0.9 \%$ after 52 weeks $(p<0.0001)$ [45]. In comparison to empagliflozin, the proportion of patients achieving $\mathrm{HbA} 1 \mathrm{c} 7 \%$ was also significantly greater in the oral semaglutide groups $(66.1 \%$ vs. $43.2 \%, p<0.0001$ ) [45]. Body weight change was $-3.8 \mathrm{~kg}$ in semaglutide and $-3.6 \mathrm{~kg}$ in empagliflozin $(p=0.6231)$; however, the trial product estimand at week 52 showed that oral semaglutide reduced body weight significantly more than empagliflozin $(-4.7$ versus $-3.8 \mathrm{~kg} ; p=0.0114$ ) [45]. Adverse events, mostly mild to moderate in severity, were reported in $70.5 \%$ and $69.2 \%$ of patients on oral semaglutide and empagliflozin, respectively [45]. Nausea was the most common side effect in the semaglutide group, with $19.8 \%$ experiencing it [45]. Oral semaglutide was found to be superior to empagliflozin in lowering $\mathrm{HbA} 1 \mathrm{c}$ and weight (trial product estimand) at week 52 in the PIONEER 2 trial, and to be as tolerable as injectable GLP-1RAs [45]. In patients with T2D who were uncontrolled on metformin alone, oral semaglutide significantly improved $\mathrm{HbA1c}$ versus empagliflozin, while fasting glucose reductions were similar in both groups, implying that changes in glycemic control are mostly due to the greater reduction of postprandial glucose with oral semaglutide. 


\subsubsection{DPP-4 Inhibitors}

In the PIONEER 3 trial, 1864 patients with T2D who were using metformin with or without sulfonylurea were compared to those using oral semaglutide versus sitagliptin [46]. For 78 weeks, patients were randomly assigned 1:1:1:1 to oral semaglutide 3, 7, or $14 \mathrm{mg}$ or sitagliptin $100 \mathrm{mg}$ [46]. The semaglutide dose was started at $3 \mathrm{mg}$ and gradually increased to the randomized dose every 4 weeks. The average age was 58 years old and the average BMI was $32.5 \mathrm{~kg} / \mathrm{m}^{2}$ [46]. Compared to $-0.8 \%$ for sitagliptin, the estimated mean changes in $\mathrm{HbA} 1 \mathrm{c}$ at week 26 for 3,7 , and $14 \mathrm{mg}$ of semaglutide were $-0.6 \%,-1.0 \%$, and $-1.3 \%$, respectively [46]. Semaglutide 7 and $14 \mathrm{mg}$ both outperformed sitagliptin in terms of glucose control $(p<0.001)$; however, semaglutide $3 \mathrm{mg}$ failed to exhibit non-inferiority to sitagliptin [43]. Semaglutide 3, 7, and $14 \mathrm{mg}$ reduced $\mathrm{HbA} 1 \mathrm{c}$ by $0.0 \%(p=0.61), 0.1 \%$ $(p=0.06)$, and $0.4 \%(p<0.001)$, respectively, at week 78 [46]. In terms of weight loss at week 78 , dosages of 3,7 , and $14 \mathrm{mg}$ of oral semaglutide outperformed sitagliptin by 0.8 , 1.7 , and $2.1 \mathrm{~kg}$ ( $p=0.02$ for $3 \mathrm{mg}$ and $p<0.001$ for 7 and $14 \mathrm{mg})$, respectively [46]. The authors found that oral semaglutide dosages of 7 and $14 \mathrm{mg}$ were superior to sitagliptin in terms of glycemic management and weight loss, and the safety profile was comparable to that of other injectable GLP-1RAs [46]. As enhanced glycemic control is linked to better diabetes-related outcomes and some patients prefer oral drugs, the results obtained with oral semaglutide may be clinically relevant.

In the PIONEER 7 trial, sitagliptin was again compared to oral semaglutide, this time with flexibly dosed oral semaglutide [47]. A total of 504 patients with uncontrolled T2D who were using one or both oral hypoglycemic drugs were randomly assigned to receive either oral semaglutide or sitagliptin [47]. Patients who were randomly assigned to the oral semaglutide group were given $3 \mathrm{mg}$ for 8 weeks and subsequently had their doses changed every 8 weeks based on their HbA1c level and tolerability [47]. The participants were $57 \%$ male and the mean age was 57.4 years [47]. At week $8,73 \%$ of participants in the semaglutide group were able to receive an increased dose of $7 \mathrm{mg}$ [47]. At week $52,9 \%, 30 \%$, and $59 \%$ of patients received oral semaglutide dosages of 3, 7, and $14 \mathrm{mg}$, respectively [47]. Semaglutide was significantly greater than sitagliptin at lowering the $\mathrm{HbA1c}$ and weight with an ETD of $-0.5 \%(p<0.0001)$ and $-1.9 \mathrm{~kg}(p<0.0001)$ [47]. There were many adverse events reported, including $78 \%$ in the oral semaglutide group and $69 \%$ in the sitagliptin group, and nausea was the most common [47]. In the PIONEER 7 trial, flexibly dosed oral semaglutide outperformed sitagliptin in lowering $\mathrm{HbA} 1 \mathrm{c}$ and body weight [47]. However, contrary to the expectations, flexible dose adjustment did not reduce the prevalence of adverse events.

\subsubsection{Injectable GLP-1RAs}

The PIONEER 4 trial compared the efficacy of oral semaglutide versus liraglutide in 711 patients with T2D during a 52 week period [48]. Patients on metformin with or without an SGLT-2 inhibitor who had a HbA1c of 7.0-9.5\% were randomly assigned 2:2:1 to oral semaglutide, subcutaneous liraglutide, or placebo [48]. Semaglutide and liraglutide doses were gradually increased to 14 and $1.8 \mathrm{mg}$, respectively [48]. At week 26, oral semaglutide lowered $\mathrm{HbA} 1 \mathrm{c}$ by $1.2 \%$, while liraglutide and placebo showed $1.1 \%$ and $0.2 \% \mathrm{HbA} 1 \mathrm{c}$ reduction, respectively ( $p=0.0645$ between semaglutide and liraglutide, $p<0.0001$ between semaglutide and placebo) [48]. Oral semaglutide, on the other hand, demonstrated a greater reduction of $\mathrm{HbA1c}$ compared to both liraglutide and placebo at week 52, with ETDs of $-0.3 \%$ compared to liraglutide $(p=0.0002)$ and $-1.0 \%$ compared to placebo $(p<0.0001)$ [48]. Additionally, oral semaglutide reduced the body weight considerably more than both liraglutide and placebo at week 26 (ETD $-1.2 \mathrm{~kg}, p=0.0003$ for liraglutide and ETD $-3.8 \mathrm{~kg}, p<0.0001$ for placebo) and week 52 (ETD $-1.3 \mathrm{~kg}, p=0.0019$ for liraglutide and ETD $-3.3 \mathrm{~kg}, p<0.0001$ for placebo) [48]. Oral semaglutide is non-inferior to subcutaneous liraglutide and superior to placebo in $\mathrm{HbA} 1 \mathrm{c}$ reduction and greater than liraglutide and placebo in weight loss; thus, oral semaglutide may be a better option for patients who refuse injectable GLP-1RA [48]. Being the first to compare oral versus 
subcutaneous GLP-1RAs for T2D, this study suggested the long-term (52-week) efficacy and safety of oral semaglutide versus subcutaneous liraglutide.

The PIONEER 9 trial, which was conducted in Japan, compared the efficacy of oral semaglutide monotherapy with that of placebo and liraglutide in 243 Japanese patients with T2D who were inadequately controlled with diet and exercise alone or one oral hypoglycemic agent that had to be washed out before starting the study drug [49]. Patients were randomly assigned to receive either 3,7 , or $14 \mathrm{mg}$ of oral semaglutide, once-daily subcutaneous liraglutide $0.9 \mathrm{mg}$ (the maximum dose allowed in Japan), or placebo [49]. Liraglutide was started at $0.3 \mathrm{mg}$ per day through subcutaneous injection and increased by $0.3 \mathrm{mg}$ every week until it reached $0.9 \mathrm{mg}$ [49]. After 26 weeks, all of the three oral semaglutide groups had considerably lower A1c levels than placebo $(p<0.0001)$, and the semaglutide $14 \mathrm{mg}$ group had significantly lower A1c levels than the liraglutide $0.9 \mathrm{mg}$ group $(p=0.0272)$ [49]. At 52 weeks, all three dosages of oral semaglutide remained superior to placebo $(p<0.0001)$, whereas the difference between oral semaglutide and liraglutide was not significant [49]. In terms of HbA1c lowering, oral semaglutide $7 \mathrm{mg}$ was comparable to liraglutide $0.9 \mathrm{mg}$, and oral semaglutide $14 \mathrm{mg}$ was superior to liraglutide $0.9 \mathrm{mg}$ in Japanese patients with T2D.

In PIONEER 10, oral semaglutide and weekly dulaglutide were compared in Japanese patients with T2D [50]. A total of 458 participants were enrolled in the study and were randomly assigned to receive semaglutide 3,7 , or $14 \mathrm{mg}$, or $0.75 \mathrm{mg}$ of dulaglutide [50]. By week 52, changes in $\mathrm{HbA} 1 \mathrm{c}$ from baseline with oral semaglutide 3, 7, and $14 \mathrm{mg}$ were $-0.9 \%,-1.4 \%$, and $-1.7 \%$, respectively, compared to $-1.4 \%$ with dulaglutide [50]. Only the $14 \mathrm{mg}$ dose of oral semaglutide was significantly superior to dulaglutide with an ETD of $-0.3 \%(p=0.0170)$ [50]. With ETDs of -1.9 and $-2.6 \mathrm{~kg}$, oral semaglutide 7 and $14 \mathrm{mg}$ showed considerable superiority to dulaglutide in terms of body weight change $(p<0.0001$ for both) [50]. Adverse events were reported in 77\% (101/131) of the oral semaglutide $3 \mathrm{mg}$ group, $80 \%(106 / 132)$ of the oral semaglutide $7 \mathrm{mg}$ group, $85 \%(111 / 130)$ of the oral semaglutide $14 \mathrm{mg}$ group, and $82 \%(52 / 65)$ of the dulaglutide group, indicating a safety profile similar to that of other GLP-1RAs [50]. The fixed dosage of dulaglutide in this experiment is a limitation, as dulaglutide can be titrated up to $1.5 \mathrm{mg}$ [50]. The authors concluded that oral semaglutide $14 \mathrm{mg}$ was superior to dulaglutide $0.75 \mathrm{mg}$ in terms of $\mathrm{HbA} 1 \mathrm{c}$ reduction and semaglutide 7 and $14 \mathrm{mg}$ in terms of weight reduction [50]. Once-daily oral semaglutide was also well-tolerated, with the incidence of adverse events similar to once-weekly subcutaneous dulaglutide.

\section{Special Populations}

In patients with T2D and renal impairment, the PIONEER 5 study compared the effectiveness and tolerability of oral semaglutide versus placebo [51]. Participants were on a stable dose of metformin and/or sulfonylurea or basal insulin with or without metformin for at least 90 days with an estimated glomerular filtration rate of $30-59 \mathrm{~mL} / \mathrm{min} / 1.73 \mathrm{~m}^{2}$ [51]. In addition to their current medication, 324 individuals were randomly allocated to receive oral semaglutide (dosage gradually increased from 3 to $14 \mathrm{mg}$ ) or placebo for 26 weeks [51]. $\mathrm{HbA1c}$ and body weight reduction showed superiority in the oral semaglutide group compared to the placebo group with an ETD of $-0.8 \%$ of HbA1c $(p<0.0001)$ and $-2.5 \mathrm{~kg}$ of body weight $(p<0.0001)$ [51]. In the oral semaglutide group, the urine albumin to creatinine ratio improved, but it worsened in the placebo group [51]. From baseline to week 26, mean systolic and diastolic blood pressures (BPs) were reduced by 7 and $2 \mathrm{mmHg}$, respectively, with statistically significant ETDs compared to placebo $(-7 \mathrm{mmHg}, p<0.0001$ for systolic $\mathrm{BP}$ and $-3 \mathrm{mmHg}, p=0.0018$ for diastolic BP) [51]. Adverse events were consistent with those of prior studies, and renal function did not alter in either treatment group during the trial [51]. Overall, oral semaglutide was efficacious and safe in individuals with renal dysfunction, demonstrating its potential as an antidiabetic medication that may improve kidney function in patients with T2D with decreased renal function [51]. 


\section{Cardiovascular Outcomes with Oral Semaglutide}

The goal of the PIONEER 6 trial was to assess the cardiovascular safety of oral semaglutide [52]. In total, 3183 patients with T2D who were receiving conventional therapy were enrolled and randomly assigned to receive either oral semaglutide or a placebo [52]. All eligible patients were at high risk of cardiovascular disease, either $\geq 50$ years with established cardiovascular or renal disease or $\geq 60$ years with cardiovascular risk factors [52]. A cardiovascular event, such as cardiovascular death, non-fatal myocardial infarction, or non-fatal stroke, was the primary outcome [52].

During the median follow-up of 15.9 months, 137 major adverse cardiovascular events (MACEs) $(61 / 1591$ patients $(3.8 \%)$ in the oral semaglutide group and 76/1592 patients $(4.8 \%)$ in the placebo group) were documented [52]. Oral semaglutide was found to be noninferior to placebo in terms of cardiovascular risk, with a difference of $21 \%$ (hazard ratio (HR) $0.79 ; p<0.001)$. However, the HR was not significant for superiority $(p=0.17)$ [52]. Nonetheless, when compared to the placebo group, death from cardiovascular causes and death from any cause were significantly lower in the oral semaglutide group (HR 0.49, $95 \%$ confidence interval (CI) $0.27-0.92$ and HR $0.51,95 \%$ CI $0.31-0.84$, respectively) [50]. Furthermore, compared to $0.3 \%$ and $0.8 \mathrm{~kg}$ in the placebo group, the oral semaglutide group had a $1.0 \%$ drop in $\mathrm{HbA} 1 \mathrm{c}$ and $4.2 \mathrm{~kg}$ weight loss [52]. As a result, the authors determined that oral semaglutide was non-inferior to placebo in terms of cardiovascular outcomes [52].

Patients in the PIONEER 6 trial had the same cardiovascular risk profile as those in the SUSTAIN 6 trial [30]. As a result, the composite primary outcome was as well-established as the first occurrence of a MACE (death from cardiovascular causes, non-fatal myocardial infarction, and non-fatal stroke). However, whereas the SUSTAIN 6 study demonstrated that subcutaneous semaglutide is superior to placebo (HR 0.74; 95\% CI 0.58-0.95), the PIONEER 6 trial could only demonstrate that oral semaglutide was non-inferior to placebo (HR 0.79; 95\% CI 0.57-1.1) [30,52]. Given that the patients' baseline characteristics were similar in both studies, the disparity in cardiovascular outcomes could have resulted from the difference in the number of cardiovascular events due to the difference in trial duration between the PIONEER 6 (137 events in 64 weeks) and SUSTAIN 6 (254 events in 104 weeks) trials [30,52]. However, the varied form of administration could be a factor for the discrepancy in cardiovascular outcomes; hence, further studies comparing oral and subcutaneous semaglutide would be beneficial.

\section{Future Perspectives}

The phase 3 randomized clinical trials PIONEER 11 and 12 are now underway in China and are expected to be finished this year. The PIONEER 11 trial compares oral semaglutide to placebo in patients with T2D who are not receiving any antidiabetic drugs. The primary outcome is the change in $\mathrm{HbA} 1 \mathrm{c}$ from baseline to week 26 [53]. The PIONEER 12 trial evaluates the efficacy and safety of oral semaglutide compared to sitagliptin in patients showing $\mathrm{HbA} 1 \mathrm{c}$ of $7-10.5 \%$ on a stable dose of metformin [54]. Again, the primary outcome is the change in $\mathrm{HbA} 1 \mathrm{c}$ from baseline to week 26 [54]. These two clinical trials will contribute to the evidence of oral semaglutide's efficacy and tolerability.

In the PIONEER 6 trial, oral semaglutide only revealed non-inferiority to placebo in terms of cardiovascular benefits; as a result, a longer-term investigation, A Heart Disease Study of Semaglutide in Patients with Type 2 Diabetes (SOUL), is currently underway [55]. SOUL has enrolled around 9640 patients with T2D and cardiovascular disease, cerebrovascular disease, symptomatic peripheral artery disease, or chronic kidney disease for 3.5-5 years [55]. In addition, the time to a MACE occurrence in patients randomized to oral semaglutide $14 \mathrm{mg}$ or placebo is being studied [55].

\section{Conclusions}

Oral semaglutide, which was approved in the United States in September 2019, has emerged as a promising therapeutic option for patients with T2D [56]. Oral semaglutide 
$14 \mathrm{mg}$ lowered $\mathrm{HbA} 1 \mathrm{c}$ substantially more than placebo, empagliflozin, sitagliptin, liraglutide, and dulaglutide in the PIONEER clinical study program. The oral semaglutide $14 \mathrm{mg}$ group lost considerably more weight than the placebo, sitagliptin, and liraglutide groups. Furthermore, oral semaglutide was well-tolerated, with an adverse event profile similar to that of subcutaneous GLP-1RAs. In the PIONEER 6 trial, cardiovascular safety was also demonstrated. As a result, oral semaglutide has been identified as a convenient and successful therapy option for patients with T2D, allowing for earlier administration of GLP-1RA.

Gut hormones, which play a key role in regulating energy balance and metabolism, are being touted as potential new antidiabetic and antiobesity therapeutic targets. Agents that interact with two or three gut hormone receptors have been demonstrated to be effective in improving insulin sensitivity and weight reduction [7,57]. Following the successful launch of the absorption enhancer in oral semaglutide, attempts to experiment with and develop hormone-based therapies will only increase. Novel medications based on gut hormones promise a bright future for the treatment of diabetes and obesity.

Author Contributions: Conceptualization, H.S.K.; investigation, H.S.K. and C.H.J.; writing—original draft preparation, H.S.K.; writing—review and editing, C.H.J. All authors have read and agreed to the published version of the manuscript.

Funding: This review was funded by the Basic Science Research Program through the National Research Foundation of Korea (NRF) funded by the Ministry of Education, grant number NRF2020R1A2C1101977, to C.H.J. These funding sources had no roles in the writing of the article or the decision to submit the article for publication.

Institutional Review Board Statement: Not applicable.

Informed Consent Statement: Not applicable.

Conflicts of Interest: The authors declare no conflict of interest.

\section{References}

1. Chatterjee, S.; Khunti, K.; Davies, M.J. Type 2 diabetes. Lancet 2017, 389, 2239-2251. [CrossRef]

2. Marx, N.; Davies, M.J.; Grant, P.J.; Mathieu, C.; Petrie, J.R.; Cosentino, F.; Buse, J.B. Guideline recommendations and the positioning of newer drugs in type 2 diabetes care. Lancet Diabetes Endocrinol. 2021, 9, 46-52. [CrossRef]

3. Buse, J.B.; Wexler, D.J.; Tsapas, A.; Rossing, P.; Mingrone, G.; Mathieu, C.; D'Alessio, D.A.; Davies, M.J. 2019 Update to: Management of Hyperglycemia in Type 2 Diabetes, 2018. A Consensus Report by the American Diabetes Association (ADA) and the European Association for the Study of Diabetes (EASD). Diabetes Care 2020, 43, 487-493. [CrossRef] [PubMed]

4. Hur, K.Y.; Moon, M.K.; Park, J.S.; Kim, S.K.; Lee, S.H.; Yun, J.S.; Baek, J.H.; Noh, J.; Lee, B.W.; Oh, T.J.; et al. 2021 Clinical Practice Guidelines for Diabetes Mellitus of the Korean Diabetes Association. Diabetes Metab. J. 2021, 45, 461-481. [CrossRef]

5. Magkos, F.; Hjorth, M.F.; Astrup, A. Diet and exercise in the prevention and treatment of type 2 diabetes mellitus. Nat. Rev. Endocrinol. 2020, 16, 545-555. [CrossRef] [PubMed]

6. Murphy, K.G.; Bloom, S.R. Gut hormones and the regulation of energy homeostasis. Nature 2006, 444, 854-859. [CrossRef] [PubMed]

7. Lee, Y.H.; Lee, H.W.; Choi, H.J. GLP-1 Based Combination Therapy for Obesity and Diabetes. J. Obes. Metab. Syndr. 2017, 26, 155-160. [CrossRef] [PubMed]

8. Gavrieli, A.; Mantzoros, C.S. Novel Molecules Regulating Energy Homeostasis: Physiology and Regulation by Macronutrient Intake and Weight Loss. Endocrinol. Metab. 2016, 31, 361-372. [CrossRef]

9. Brennan, I.M.; Luscombe-Marsh, N.D.; Seimon, R.V.; Otto, B.; Horowitz, M.; Wishart, J.M.; Feinle-Bisset, C. Effects of fat, protein, and carbohydrate and protein load on appetite, plasma cholecystokinin, peptide $Y Y$, and ghrelin, and energy intake in lean and obese men. Am. J. Physiol. Gastrointest Liver Physiol. 2012, 303, G129-G140. [CrossRef]

10. Yu, J.H.; Kim, M.S. Molecular mechanisms of appetite regulation. Diabetes Metab. J. 2012, 36, 391-398. [CrossRef]

11. Day, J.W.; Ottaway, N.; Patterson, J.T.; Gelfanov, V.; Smiley, D.; Gidda, J.; Findeisen, H.; Bruemmer, D.; Drucker, D.J.; Chaudhary, N.; et al. A new glucagon and GLP-1 co-agonist eliminates obesity in rodents. Nat. Chem. Biol. 2009, 5, 749-757. [CrossRef]

12. Wynne, K.; Park, A.; Small, C.; Meeran, K.; Ghatei, M.; Frost, G.; Bloom, S. Oxyntomodulin increases energy expenditure in addition to decreasing energy intake in overweight and obese humans: A randomised controlled trial. Int. J. Obes. 2006, 30, 1729-1736. [CrossRef] [PubMed]

13. Shankar, S.S.; Shankar, R.R.; Mixson, L.A.; Miller, D.L.; Pramanik, B.; O’Dowd, A.K.; Williams, D.M.; Frederick, C.B.; Beals, C.R.; Stoch, S.A.; et al. Native Oxyntomodulin Has Significant Glucoregulatory Effects Independent of Weight Loss in Obese Humans with and without Type 2 Diabetes. Diabetes 2018, 67, 1105-1112. [CrossRef] [PubMed] 
14. Gribble, F.M.; Reimann, F. Function and mechanisms of enteroendocrine cells and gut hormones in metabolism. Nat. Rev. Endocrinol. 2019, 15, 226-237. [CrossRef] [PubMed]

15. Tasyurek, H.M.; Altunbas, H.A.; Balci, M.K.; Sanlioglu, S. Incretins: Their physiology and application in the treatment of diabetes mellitus. Diabetes Metab. Res. Rev. 2014, 30, 354-371. [CrossRef] [PubMed]

16. Nauck, M.A.; Meier, J.J. Incretin hormones: Their role in health and disease. Diabetes Obes. Metab. 2018,20 (Suppl. 1), 5-21. [CrossRef]

17. Kieffer, T.J.; Habener, J.F. The glucagon-like peptides. Endocr. Rev. 1999, 20, 876-913. [CrossRef] [PubMed]

18. Nauck, M.A.; Heimesaat, M.M.; Orskov, C.; Holst, J.J.; Ebert, R.; Creutzfeldt, W. Preserved incretin activity of glucagon-like peptide 1 [7-36 amide] but not of synthetic human gastric inhibitory polypeptide in patients with type-2 diabetes mellitus. J. Clin. Investig. 1993, 91, 301-307. [CrossRef]

19. Christensen, M.; Vedtofte, L.; Holst, J.J.; Vilsbøll, T.; Knop, F.K. Glucose-dependent insulinotropic polypeptide: A bifunctional glucose-dependent regulator of glucagon and insulin secretion in humans. Diabetes 2011, 60, 3103-3109. [CrossRef]

20. Nauck, M.; Kemmeries, G.; Holst, J.; Meier, J. Rapid tachyphylaxis of the glucagon-like peptide 1-induced deceleration of gastric emptying in humans. Diabetes 2011, 60, 1561-1565. [CrossRef]

21. Campbell, J.E.; Drucker, D.J. Pharmacology, physiology, and mechanisms of incretin hormone action. Cell Metab. 2013, 17, 819-837. [CrossRef]

22. Baggio, L.L.; Drucker, D.J. Biology of incretins: GLP-1 and GIP. Gastroenterology 2007, 132, 2131-2157. [CrossRef]

23. Spain, C.V.; Wright, J.J.; Hahn, R.M.; Wivel, A.; Martin, A.A. Self-reported Barriers to Adherence and Persistence to Treatment with Injectable Medications for Type 2 Diabetes. Clin. Ther. 2016, 38, 1653-1664.e1. [CrossRef]

24. Guerci, B.; Chanan, N.; Kaur, S.; Jasso-Mosqueda, J.G.; Lew, E. Lack of Treatment Persistence and Treatment Nonadherence as Barriers to Glycaemic Control in Patients with Type 2 Diabetes. Diabetes Ther. 2019, 10, 437-449. [CrossRef]

25. Kapitza, C.; Nosek, L.; Jensen, L.; Hartvig, H.; Jensen, C.B.; Flint, A. Semaglutide, a once-weekly human GLP-1 analog, does not reduce the bioavailability of the combined oral contraceptive, ethinylestradiol/levonorgestrel. J. Clin. Pharmacol. 2015, 55, 497-504. [CrossRef] [PubMed]

26. Sorli, C.; Harashima, S.I.; Tsoukas, G.M.; Unger, J.; Karsbøl, J.D.; Hansen, T.; Bain, S.C. Efficacy and safety of once-weekly semaglutide monotherapy versus placebo in patients with type 2 diabetes (SUSTAIN 1): A double-blind, randomised, placebocontrolled, parallel-group, multinational, multicentre phase 3a trial. Lancet Diabetes Endocrinol. 2017, 5, 251-260. [CrossRef]

27. Ahrén, B.; Masmiquel, L.; Kumar, H.; Sargin, M.; Karsbøl, J.D.; Jacobsen, S.H.; Chow, F. Efficacy and safety of once-weekly semaglutide versus once-daily sitagliptin as an add-on to metformin, thiazolidinediones, or both, in patients with type 2 diabetes (SUSTAIN 2): A 56-week, double-blind, phase 3a, randomised trial. Lancet Diabetes Endocrinol. 2017, 5, 341-354. [CrossRef]

28. Ahmann, A.J.; Capehorn, M.; Charpentier, G.; Dotta, F.; Henkel, E.; Lingvay, I.; Holst, A.G.; Annett, M.P.; Aroda, V.R. Efficacy and Safety of Once-Weekly Semaglutide Versus Exenatide ER in Subjects with Type 2 Diabetes (SUSTAIN 3): A 56-Week, Open-Label, Randomized Clinical Trial. Diabetes Care 2018, 41, 258-266. [CrossRef] [PubMed]

29. Aroda, V.R.; Bain, S.C.; Cariou, B.; Piletič, M.; Rose, L.; Axelsen, M.; Rowe, E.; DeVries, J.H. Efficacy and safety of once-weekly semaglutide versus once-daily insulin glargine as add-on to metformin (with or without sulfonylureas) in insulin-naive patients with type 2 diabetes (SUSTAIN 4): A randomised, open-label, parallel-group, multicentre, multinational, phase 3a trial. Lancet Diabetes Endocrinol. 2017, 5, 355-366.

30. Pratley, R.E.; Aroda, V.R.; Lingvay, I.; Lüdemann, J.; Andreassen, C.; Navarria, A.; Viljoen, A. Semaglutide versus dulaglutide once weekly in patients with type 2 diabetes (SUSTAIN 7): A randomised, open-label, phase 3b trial. Lancet Diabetes Endocrinol. 2018, 6, 275-286. [CrossRef]

31. Marso, S.P.; Bain, S.C.; Consoli, A.; Eliaschewitz, F.G.; Jódar, E.; Leiter, L.A.; Lingvay, I.; Rosenstock, J.; Seufert, J.; Warren, M.L.; et al. Semaglutide and Cardiovascular Outcomes in Patients with Type 2 Diabetes. N. Engl. J. Med. 2016, 375, 1834-1844. [CrossRef]

32. Beglinger, C.; Poller, B.; Arbit, E.; Ganzoni, C.; Gass, S.; Gomez-Orellana, I.; Drewe, J. Pharmacokinetics and pharmacodynamic effects of oral GLP-1 and PYY3-36: A proof-of-concept study in healthy subjects. Clin. Pharmacol. Ther. 2008, 84, 468-474. [CrossRef]

33. Andersen, A.; Knop, F.K.; Vilsbøll, T. A Pharmacological and Clinical Overview of Oral Semaglutide for the Treatment of Type 2 Diabetes. Drugs 2021, 81, 1003-1030. [CrossRef] [PubMed]

34. Buckley, S.T.; Bækdal, T.A.; Vegge, A.; Maarbjerg, S.J.; Pyke, C.; Ahnfelt-Rønne, J.; Madsen, K.G.; Schéele, S.G.; Alanentalo, T.; Kirk, R.K.; et al. Transcellular stomach absorption of a derivatized glucagon-like peptide-1 receptor agonist. Sci. Transl. Med. 2018, 10, eaar7047. [CrossRef] [PubMed]

35. Bækdal, T.A.; Breitschaft, A.; Donsmark, M.; Maarbjerg, S.J.; Søndergaard, F.L.; Borregaard, J. Effect of Various Dosing Conditions on the Pharmacokinetics of Oral Semaglutide, a Human Glucagon-Like Peptide-1 Analogue in a Tablet Formulation. Diabetes Ther. 2021, 12, 1915-1927. [CrossRef]

36. Baekdal, T.A.; Thomsen, M.; Kupčová, V.; Hansen, C.W.; Anderson, T.W. Pharmacokinetics, Safety, and Tolerability of Oral Semaglutide in Subjects with Hepatic Impairment. J. Clin. Pharmacol. 2018, 58, 1314-1323. [CrossRef] [PubMed]

37. Granhall, C.; Søndergaard, F.L.; Thomsen, M.; Anderson, T.W. Pharmacokinetics, Safety and Tolerability of Oral Semaglutide in Subjects with Renal Impairment. Clin. Pharm. 2018, 57, 1571-1580. [CrossRef] 
38. Bækdal, T.A.; Breitschaft, A.; Navarria, A.; Hansen, C.W. A randomized study investigating the effect of omeprazole on the pharmacokinetics of oral semaglutide. Expert Opin. Drug Metab. Toxicol. 2018, 14, 869-877. [CrossRef] [PubMed]

39. Bækdal, T.A.; Borregaard, J.; Hansen, C.W.; Thomsen, M.; Anderson, T.W. Effect of Oral Semaglutide on the Pharmacokinetics of Lisinopril, Warfarin, Digoxin, and Metformin in Healthy Subjects. Clin. Pharm. 2019, 58, 1193-1203. [CrossRef]

40. Jordy, A.B.; Albayaty, M.; Breitschaft, A.; Anderson, T.W.; Christiansen, E.; Houshmand-Øregaard, A.; Manigandan, E.; Bækdal, T.A. Effect of Oral Semaglutide on the Pharmacokinetics of Levonorgestrel and Ethinylestradiol in Healthy Postmenopausal Women and Furosemide and Rosuvastatin in Healthy Subjects. Clin Pharm. 2021, 60, 1171-1185. [CrossRef]

41. Hauge, C.; Breitschaft, A.; Hartoft-Nielsen, M.L.; Jensen, S.; Bækdal, T.A. Effect of oral semaglutide on the pharmacokinetics of thyroxine after dosing of levothyroxine and the influence of co-administered tablets on the pharmacokinetics of oral semaglutide in healthy subjects: An open-label, one-sequence crossover, single-center, multiple-dose, two-part trial. Expert Opin. Drug Metab. Toxicol. 2021, 17, 1139-1148.

42. Aroda, V.R.; Saugstrup, T.; Buse, J.B.; Donsmark, M.; Zacho, J.; Davies, M.J. Incorporating and interpreting regulatory guidance on estimands in diabetes clinical trials: The PIONEER 1 randomized clinical trial as an example. Diabetes Obes. Metab. 2019, 21, 2203-2210. [CrossRef] [PubMed]

43. Aroda, V.R.; Rosenstock, J.; Terauchi, Y.; Altuntas, Y.; Lalic, N.M.; Morales Villegas, E.C.; Jeppesen, O.K.; Christiansen, E.; Hertz, C.L.; Haluzík, M. PIONEER 1: Randomized Clinical Trial of the Efficacy and Safety of Oral Semaglutide Monotherapy in Comparison with Placebo in Patients with Type 2 Diabetes. Diabetes Care 2019, 42, 1724-1732. [CrossRef] [PubMed]

44. Zinman, B.; Aroda, V.R.; Buse, J.B.; Cariou, B.; Harris, S.B.; Hoff, S.T.; Pedersen, K.B.; Tarp-Johansen, M.J.; Araki, E. Efficacy, Safety, and Tolerability of Oral Semaglutide Versus Placebo Added to Insulin with or without Metformin in Patients with Type 2 Diabetes: The PIONEER 8 Trial. Diabetes Care 2019, 42, 2262-2271. [CrossRef] [PubMed]

45. Rodbard, H.W.; Rosenstock, J.; Canani, L.H.; Deerochanawong, C.; Gumprecht, J.; Lindberg, S.; Lingvay, I.; Søndergaard, A.L.; Treppendahl, M.B.; Montanya, E. Oral Semaglutide Versus Empagliflozin in Patients with Type 2 Diabetes Uncontrolled on Metformin: The PIONEER 2 Trial. Diabetes Care 2019, 42, 2272-2281. [CrossRef] [PubMed]

46. Rosenstock, J.; Allison, D.; Birkenfeld, A.L.; Blicher, T.M.; Deenadayalan, S.; Jacobsen, J.B.; Serusclat, P.; Violante, R.; Watada, H.; Davies, M. Effect of Additional Oral Semaglutide vs Sitagliptin on Glycated Hemoglobin in Adults with Type 2 Diabetes Uncontrolled with Metformin Alone or with Sulfonylurea: The PIONEER 3 Randomized Clinical Trial. Jama 2019, 321, 1466-1480. [CrossRef]

47. Pieber, T.R.; Bode, B.; Mertens, A.; Cho, Y.M.; Christiansen, E.; Hertz, C.L.; Wallenstein, S.O.R.; Buse, J.B. Efficacy and safety of oral semaglutide with flexible dose adjustment versus sitagliptin in type 2 diabetes (PIONEER 7): A multicentre, open-label, randomised, phase 3a trial. Lancet Diabetes Endocrinol. 2019, 7, 528-539. [CrossRef]

48. Pratley, R.; Amod, A.; Hoff, S.T.; Kadowaki, T.; Lingvay, I.; Nauck, M.; Pedersen, K.B.; Saugstrup, T.; Meier, J.J. Oral semaglutide versus subcutaneous liraglutide and placebo in type 2 diabetes (PIONEER 4): A randomised, double-blind, phase 3a trial. Lancet 2019, 394, 39-50. [CrossRef]

49. Yamada, Y.; Katagiri, H.; Hamamoto, Y.; Deenadayalan, S.; Navarria, A.; Nishijima, K.; Seino, Y. Dose-response, efficacy, and safety of oral semaglutide monotherapy in Japanese patients with type 2 diabetes (PIONEER 9): A 52-week, phase 2/3a, randomised, controlled trial. Lancet Diabetes Endocrinol. 2020, 8, 377-391. [CrossRef]

50. Yabe, D.; Nakamura, J.; Kaneto, H.; Deenadayalan, S.; Navarria, A.; Gislum, M.; Inagaki, N. Safety and efficacy of oral semaglutide versus dulaglutide in Japanese patients with type 2 diabetes (PIONEER 10): An open-label, randomised, active-controlled, phase 3a trial. Lancet Diabetes Endocrinol. 2020, 8, 392-406. [CrossRef]

51. Mosenzon, O.; Blicher, T.M.; Rosenlund, S.; Eriksson, J.W.; Heller, S.; Hels, O.H.; Pratley, R.; Sathyapalan, T.; Desouza, C. Efficacy and safety of oral semaglutide in patients with type 2 diabetes and moderate renal impairment (PIONEER 5): A placebo-controlled, randomised, phase 3a trial. Lancet Diabetes Endocrinol. 2019, 7, 515-527. [CrossRef]

52. Husain, M.; Birkenfeld, A.L.; Donsmark, M.; Dungan, K.; Eliaschewitz, F.G.; Franco, D.R.; Jeppesen, O.K.; Lingvay, I.; Mosenzon, O.; Pedersen, S.D.; et al. Oral Semaglutide and Cardiovascular Outcomes in Patients with Type 2 Diabetes. N. Engl. J. Med. 2019, 381, 841-851. [CrossRef] [PubMed]

53. A Research Study Comparing a New Medicine Oral Semaglutide to Placebo in People with Type 2 Diabetes (PIONEER 11). Available online: https:/ / clinicaltrials.gov/ct2/show/NCT04109547 (accessed on 11 August 2021).

54. A Research Study Comparing a New Medicine Oral Semaglutide to Sitagliptin in People with Type 2 Diabetes (PIONEER 12). Available online: https:/ / clinicaltrials.gov/ct2/show/NCT04017832 (accessed on 11 August 2021).

55. A Heart Disease Study of Semaglutide in Patients with Type 2 Diabetes (SOUL). Available online: https://clinicaltrials.gov/ct2 / show / NCT03914326 (accessed on 11 August 2021).

56. Rybelsus (Semaglutide) [US Prescribing Information]. Available online: http://www.novo-pi.com/rybelsus.pdf (accessed on 6 August 2021).

57. Artasensi, A.; Pedretti, A.; Vistoli, G.; Fumagalli, L. Type 2 Diabetes Mellitus: A Review of Multi-Target Drugs. Molecules 2020, 25, 1987. [CrossRef] [PubMed] 